\title{
Accelerated Decline in Javelin Throwing Performance in Master Athletes 70 Years and Older - Do Changes in Technique Play a Role?
}

\section{(c) (i)}

\author{
Authors \\ Bergita Ganse', Hans Degens ${ }^{2,3}$
}

\author{
Affiliations \\ 1 Department of Orthopaedic Trauma Surgery, RWTH \\ Aachen University Hospital, Aachen, Germany \\ 2 Manchester Metropolitan University, School of Health- \\ care Science, Manchester, United Kingdom \\ 3 Institute of Sport Science and Innovations, Lithuanian \\ Sports University, Kaunas, Lithuania
}

\author{
Keywords \\ age, athletics, video, biomechanics, ageing, javelin, \\ throwing \\ $\begin{array}{lr}\text { received } & 05.02 .2018 \\ \text { revised } & 14.05 .2018 \\ \text { accepted } & 16.05 .2018\end{array}$ \\ Bibliography \\ DOI https://doi.org/10.1055/a-0635-0584 \\ Sports Medicine International Open 2018; 2: E79-E83 \\ (c) Georg Thieme Verlag KG Stuttgart · New York \\ ISSN 2367-1890 \\ Correspondence \\ Dr. Bergita Ganse \\ Department of Orthopaedic Trauma Surgery \\ RWTH Aachen University Hospital \\ Pauwelsstr. 30 \\ Aachen, 52074 \\ Germany \\ Tel.: + 49/241/8035 024, Fax: + 49/241/803388360 \\ bganse@ukaachen.de
}

\begin{abstract}
While many older adults are immobile and frail, others still participate in competitive sports. World records of javelin throw decrease with increasing age. It is, however, unknown 1) whether the decline is linear or, as in sprint performance, accelerates beyond the age of 69; and 2) to what extent frailty-related changes in throwing technique contribute to decreasing performance. We plotted current world records against age and assessed the performance of 27 male javelin throwers 69 years and older during three master athletics championships. Three to six throws were filmed, and the best throw of each athlete selected. A step-wise linear regression was applied to assess contributions of age, angle of release, angle of attitude, angle of attack and elbow angle just before the pull to performance. The ageing-related decline in javelin-throw performance accelerated after age 69 . Age was the main predictor of performance (adjusted $R^{2}=0.68$ ), with a small contribution of elbow angle (adjusted $R^{2}$ increased to 0.76 ) and angle of attack $\left(R^{2}=0.82\right.$; all $\left.P<0.001\right)$ in the older athletes. None of the technique-related parameters correlated with age. Although the technique had some influence on javelin-throwing performance, the accelerated decline was not associated with a characteristic ageing-related change in technique.
\end{abstract}

\section{Introduction}

Javelin throwing was already part of the pentathlon in the first modern Olympic Games in Athens in 1896 and became a separate event in the Olympic Games in 1908. Unlike other throwing events, not only arm, upper body and core strength are required, but also speed and agility $[12,19]$. Indeed, javelin throwing consists of an approach run and the subsequent release of the javelin. The speed of the approach run (a run-up and two or three cross-over steps) is an important factor for the success of a javelin throw. The approach run is followed by the release phase (one-legged and two-legged support phase) and braking phase [15]. The second-last cross-over step, the impulse step, allows the centre of mass to be above the rear leg to prepare for a long acceleration path and the strike. A high velocity at release and an angle of release (the direction of pull) between $32^{\circ}$ and $36^{\circ}$ have been associated with good results [12]. Further important factors are the elbow angle, which should ideally be $180^{\circ}$, and the angle of attitude (the angle between the longitudinal axis of the javelin and the horizontal line at moment 


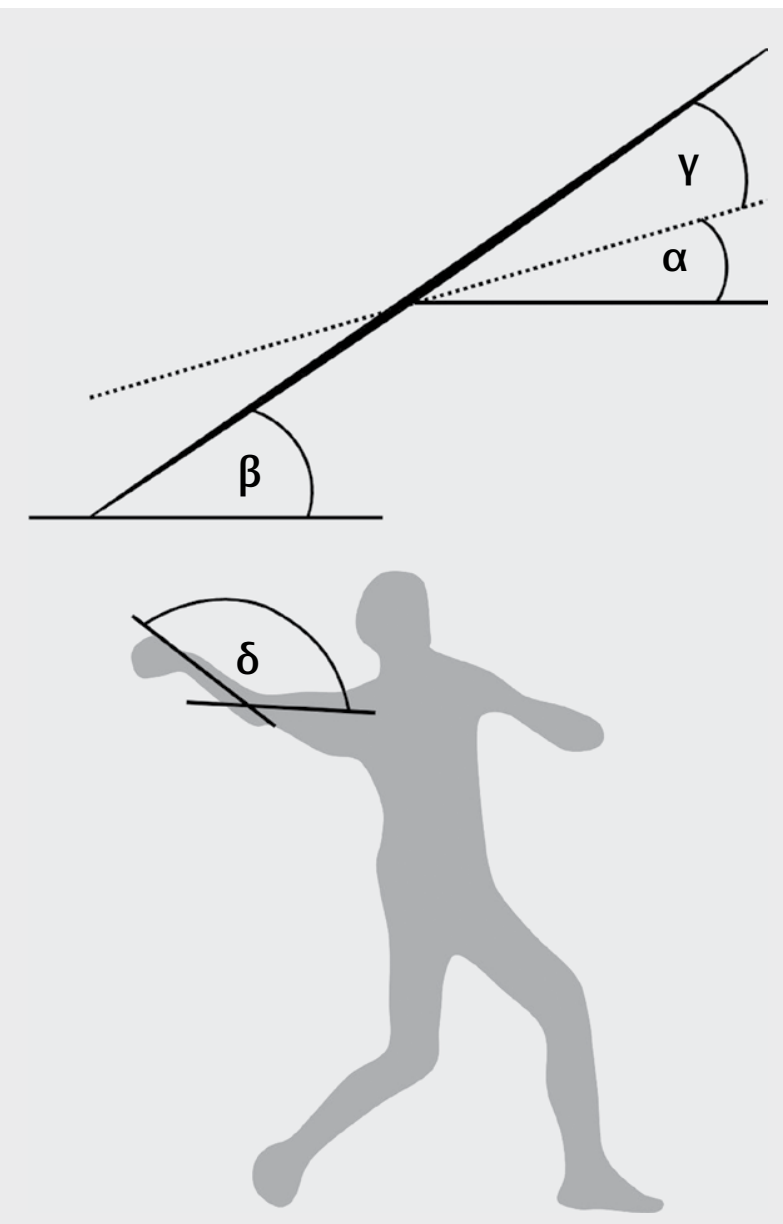

- Fig. 1 Angles of interest during javelin throwing: $\boldsymbol{\alpha}$ : angle of release, $\boldsymbol{\beta}$ : angle of attitude, $\boldsymbol{\gamma}$ : angle of attack, $\boldsymbol{\delta}$ : elbow angle just before the pull.

of release; see $>$ Fig. 1). The difference between the angle of attitude and the angle of release is called the angle of attack [15] and should be as low as possible to enhance the energy transfer to the javelin [12].

In recent years, master athletics, competitions for any athlete older than 35 years, has gained growing popularity, including participation in international javelin throwing competitions. In many other events, an accelerated decline in performance was shown after the age of $70[3,5,11]$ that is at least partly attributable to an ageing-related reduction in pulmonary function $[6,7]$, loss of muscle strength and reduction in tendon stiffness $[1,10]$, and loss of motor units $[8,16]$. It is not known, however, whether such an accelerated ageing-related decline in older age also occurs in the performance of javelin throwing, because performance is not only determined by physiological factors, but also, as discussed above, by technique.

Although many studies have been conducted on javelinthrowing techniques and biomechanics in young and well-performing athletes $[2,12,14,19,20]$, as far as we know there are no studies in older javelin throwers. Master javelin throwers may well change their technique to compensate for deficits in muscle strength, speed and agility, and to minimise pain during some movements.
Ageing-related changes in throwing technique within the older master athlete population may thus cause larger decrements in performance than expected from physiological changes alone. Understanding their throwing behaviour and biomechanical differences from young athletes is not only important for training and competition purposes, but also interesting for the understanding of movement and musculoskeletal and neuronal changes during the ageing process.

The aim of the present study was to assess ageing-related changes in javelin-throwing performance using the performances of master javelin throwers in three master athletics competitions. In addition, we sought to determine to what extent throwing technique contributes to performance in $69^{+}$-year-old male master javelin throwers and whether the technique shows ageing-related changes in this population of athletes. It was hypothesized that javelinthrowing performance shows an accelerated decline after the age of 69 years.

\section{Materials and Methods}

Ethical approval was obtained from RWTH Aachen University Hospital IRB (reference number EK 178/17, date of approval: August 3, 2017). Ethical standards were according to international standards as required by the journal [9]. Informed consent was not needed, as data were collected during three master javelin-throwing competitions and anonymised before analysis, according to the declaration of Helsinki. To maintain anonymity of athletes, details on the place and date of competitions are not reported.

\section{Age groups}

In master athletics, participants are allocated to 5-year age groups. For example, all male athletes between 80 and 84 years of age are in age group $\mathrm{M} 80$, and a 78-year-old male athlete is allocated to age group M75. The mass of the javelin decreases with age. While the javelin for men up to 49 years weighs $800 \mathrm{~g}$, its weight drops each decade, where men of 70-79 years of age use a 500-g javelin, and athletes 80 years and older throw a 400 -g javelin. For the first part of the study, we retrieved the current world records for men in each age group [21] and recorded the performance of all male javelin-throwers who participated in the three competitions. Age-graded performance (AGP) was reported as a percentage of the world record at the corresponding age. We also calculated the predicted performance for each of the 27 athletes, using a regression equation of performance vs. age in the study population of 27 male $69^{+}$-year-old javelin throwers. Five of these athletes participated in age class M70, eight in M75, eleven in M80 and three in M85.

\section{Inclusion and exclusion criteria}

The inclusion criterion was participation in the javelin-throw competition in age class M70 or older. To participate in the competitions, athletes did not have to qualify, but they had to be registered with a track and field club. Three to six throws of 27 male $69^{+}$-yearold javelin throwers were filmed for later video analysis as described below. The best attempt of each athlete was selected for analysis. In some cases, analysis of the video images of the best throw was impossible when people standing or walking between the athlete and camera obstructed the field of view. In those cases, the next 
best attempt was selected. Weather conditions were fine in each of the three competitions without rain or significant wind.

\section{Video analysis}

A Canon EOS 60D camera with a Canon EF 75-300 mm zoom lens was used for filming (full HD 1920×1080 px, 25 fps). The camera was positioned as illustrated in $\mathbf{F i g}$. 2. Screenshots were made of the video files and angles were calculated. The number of steps was counted. When an athlete walked before running, only the steps of the run were counted. When an athlete only walked, the total number of steps was counted. - Fig. 1 shows which angles were measured and used for statistical analysis. Effects of wind were ignored. The angle of attack was calculated as: angle of attack = angle of attitude - angle of release.

\section{Statistical analysis}

SPSS (v. 23 IBM) was used for analysis. Linear regression was performed for javelin world-records vs. age, and for the actual performance or AGP in three athletic events vs. age for the 35- to 69-year-olds and $69^{+}$-year-old athletes, separately. A stepwise linear regression was done to assess to what extent performance (actual performance (in $\mathrm{m}$ ), AGP and percentage of predicted performance) was determined by age, angle of attack, angle of release, angle of attitude, elbow angle and steps. These factors were fed into the model only if they correlated with performance at $P<0.05$. The adjusted $R^{2}$ is presented. Significance was assumed at $P<0.05$. An excel file with the data can be found in the Figshare online data repository at the following URL: https://figshare.com/articles/supplement_xlsx/5661676

\section{Results}

Fig. 3a shows a linear decline $\left(R^{2}=0.97 ; P<0.001\right)$ in javelinthrowing world-records. In our population, the ageing-related decline in distance thrown was accelerated after age 69 years ( $\mathbf{F i g . ~} \mathbf{3 b}$ ),

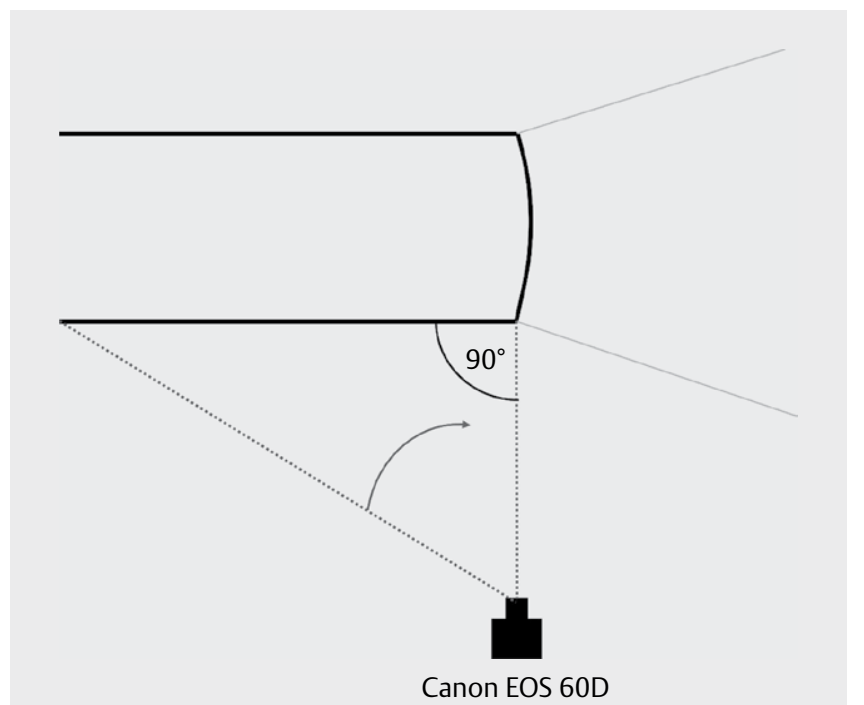

- Fig. 2 Runway and camera position seen from above. The camera was positioned at a $90^{\circ}$ angle to the arc line ending the runway. The sector covers a $28.96^{\circ}$ angle; the runway is $4 \mathrm{~m}$ wide and at least $30 \mathrm{~m}$ long. and the AGP decreased with age ( $\triangleright$ Fig. $\mathbf{3 c}$ ). The latter indicates that younger athletes on average performed better than older athletes in comparison to their age group's world record.

Stepwise linear regression showed age as the most important predictor of actual performance in the athletes 70 years and older $\left(R^{2}=0.68 ; P<0.001\right)$, facilitated by elbow angle $\left(R^{2}\right.$ increased to $0.76)$ and angle of attack $\left(R^{2}=0.82\right)$. To exclude the influence of age, we repeated the analysis for the age-graded performance (AGP). It appeared that elbow angle was the most important determinant of $A G P\left(R^{2}=0.34 ; P \leq 0.001\right)$, with additional contributions of age $\left(R^{2}=0.49\right)$ and angle of attack $\left(R^{2}=0.60\right)$. As age still appeared as a factor, we repeated the analysis with the predicted performance derived from the regression equation of distance thrown vs. age in the older athletes. In that case, elbow angle was
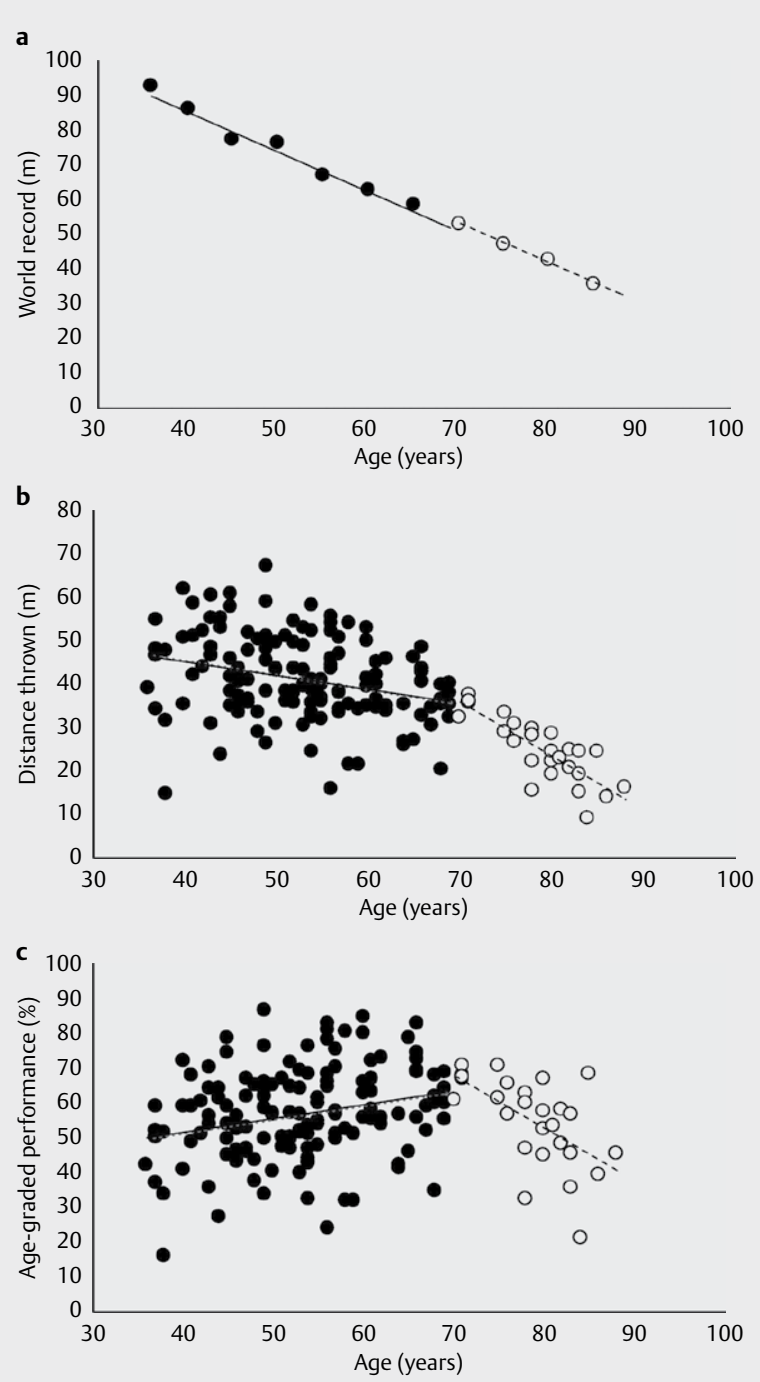

- Fig. 3 a Javelin-throwing world-records (numbers taken from [21] on August 8th, 2017) correlate negatively with age $\left(R^{2}=0.97\right.$; $\mathrm{P}<0.001)$. $\mathbf{b}$ Javelin-throwing performance in athletes participating in the three competitions. The ageing-related decline is faster after the age of 69 years (slope younger athletes: $-0.32 \mathrm{~m} \cdot \mathrm{y}^{-1}$; after 69 years: $\left.-1.25 \mathrm{~m} \cdot \mathrm{y}^{-1}\right)$. c Age-graded performance in the participating athletes. 


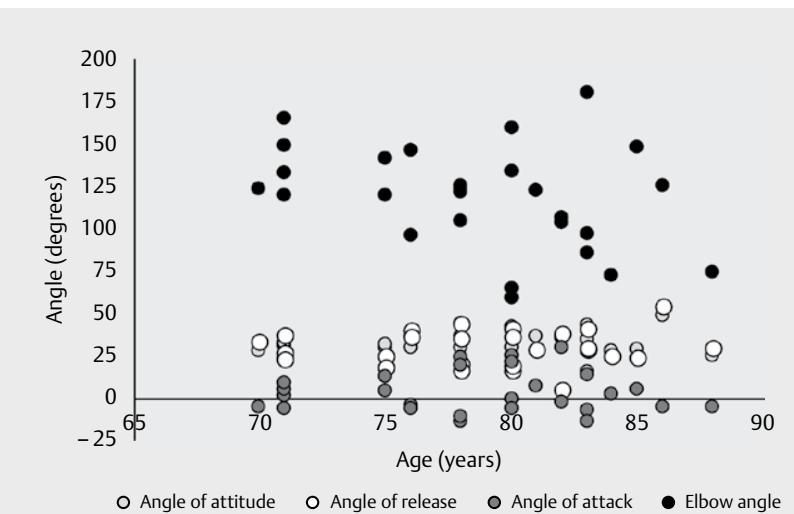

- Fig. 4 The elbow angle, angle of attitude, angle of attack and angle of release in male $69^{+}$-year-old javelin throwers.

the most important determinant of performance $\left(R^{2}=0.212\right.$; $P=0.009)$ facilitated by angle of attack $\left(R^{2}=0.341\right)$.

Neither the number of steps, nor the angles of attitude, release and attack, nor elbow angle showed a significant correlation with age (• Fig. 4).

\section{Discussion}

In the present study, 27 master athletes, age 69 years and older, were filmed during javelin-throw championships and their throwing technique was analyzed. The main observation is an accelerated ageing-related decline in javelin throwing performance after the age of 69 years, both in terms of distance thrown and age-graded performance. Although performance was to some extent determined by technique, by the elbow angle before the pull and angle of attack, there was no ageing-related change in technique in the $69^{+}$-year-old male javelin throwers. The accelerated decline in javelin throwing performance is therefore most likely related to accelerated ageing-related declines in physiological function, such as muscle strength, and/or prevention of pain during the event.

\section{Javelin-throwing performance}

While javelin-throwing world-records show a linear decrease with age [21], the ageing-related decline in the athletes who participated in the three competitions in 2017 showed an accelerated decline after the age of 69 years. This is in line with the accelerated decline observed around the same age in sprint time and endurance performance in cross-sectional $[11,17]$ and longitudinal studies $[3,5]$. In addition, the age-graded performance of javelin throwers decreased after the age of 69 years, but little before that. As an explanation of this phenomenon, the world records in the older age groups are much more influenced by individuals who have the optimal genetic constitution to perform well than in younger age groups. Alternatively, pain and/or other physical limitations may affect athletes in varying degrees. Finally, after retirement, some people seem to develop an increased interest in athletics who were previously not or little involved. Compared to athletes who continuously participated, those people would probably perform less, as they neither have the experience and routine, nor maintained their training throughout life. This group of athletes is an interesting subject for future studies.

\section{Throwing techniques in older athletes compared to those reported in younger athletes}

The angle of attitude is known to be an important factor for success in javelin throwing $[12,19,20]$ and ranges between $36^{\circ}$ and $48^{\circ}[3]$ in young elite athletes. In the present study, the average attitude angle of athletes in the $69^{+}$age group was lower than average $\left(32.5^{\circ}\right)$. A similar situation applies to the angle of release, which has been reported between $33^{\circ}$ and $38^{\circ}$ in 20- to 35-year-old athletes [15], but was only $29.6^{\circ}$ in our $69^{+}$-year-old athlete population. Because a high angle of release results in a high flight path when the javelin is thrown at high velocity, the inability to release the javelin at high velocity may thus be compensated by a lower angle of release. In older athletes who cannot release the javelin at a high enough velocity, a high angle of release will cause the javelin to land with the rear end first, making the throw invalid.

Another relevant factor might be the angle of the elbow before starting to pull and release. The average angle of the elbow just before the pull was $118.3^{\circ}$, although ideally it should be $180^{\circ}$. A lower angle of the elbow will lead to an elevation of the javelin and a flatter release angle may thus be an additional compensation for the inability to release the javelin at a high velocity. In addition, older athletes may not be able to keep their arms straight due to chronic damage to, or pain in, their shoulder and elbow joints [18], muscle weakness, lack of training in throwing techniques and/or, as discussed above for the release angle, an adaptation in throwing technique to prevent invalid throws.

The angle of attack should be as small as possible and reflects how well the impulse is transferred to the javelin $[12,15]$. Indeed, in 12 Swiss decathletes and two world-class specialists the better throwers had a lower angle of attack [12], and elite javelin throwers had smaller angles [15] that were occasionally even negative [20]. Angles of attack of the master athletes in the present study $\left(3.5^{\circ}+1-12.4^{\circ}\right)$ were also occasionally negative and in the range seen in younger athletes, suggesting the angle of attack per se does not explain lower performance of the older compared to younger javelin throwers.

The performance of javelin throwing has been reported to be positively related to the athlete's running speed $[12,15,20]$. In elite athletes, the length of the approach run varies between 26 and 36 meters and running speed is between 6.0 to $7.3 \mathrm{~m} / \mathrm{s}$ in men [15]. This distance was much shorter for our older athletes, and some even threw the javelin from a standing position, missing the impulse from the body to thrust the javelin forward.

The above observations do suggest that part of the lower performance in $69^{+}$-year-old compared to 30 - to 69 -year-old master javelin throwers can be attributed to a difference in technique. The positive relationship between elbow angle and angle of attack with performance within the $69^{+}$-year-old male javelin throwers does not explain an accelerated decline in performance because there was no correlation with age for these parameters. Most likely, the accelerated decline is attributable to a loss of muscle power, which in leg muscles has been shown to result in a decreased 6-min walking distance and timed up-and-go performance only if it decreased below a certain threshold level $[13,18]$. 


\section{Study limitation}

Javelin throwing is a three-dimensional and complex movement [4], and the analysis of the present study was performed only in two dimensions. However, the camera had a high resolution with exceptional video quality and was positioned perpendicular to the direction of throw, maximising the visibility of the angles in the plane of interest. Another limitation is the purely male cohort. The study is, however, unique because $69^{+}$-year-old javelin throwers were filmed during actual competitions.

\section{Conclusion}

In conclusion, the decline in javelin-throwing performance accelerates after the age of 69 years. Although performance was to some extent determined by technique, and especially the elbow angle before the pull and the angle of attack, the accelerated ageing-related decline in $69^{+}$-year-old male javelin throwers was only marginally attributable to ageing-related changes in technique after the age of 69 years. In explanation, we suggest the accelerated decline in javelin throwing performance (after the age of 69) is caused by accelerated ageing-related declines in physiological function, such as muscle strength, and/or the prevention of pain during the event. Practical implications of the study include 1) the theory of a linear decline in performance at high age needs to be revised and a more rapid decline is expected beyond the age of 69 years; 2 ) in older master athletes, javelin throwing performance is determined by physiological function and to some extent by technique; and 3) the javelin throwing technique employed is independent of age.

\section{Future investigations}

To answer the question of whether the accelerated decline beyond age 69 is real or caused by increased participation after retirement more research is required. Larger groups of athletes and the individual athlete's longitudinal development should be analysed. Research should be extended to a variety of sports and disciplines to allow a more thorough view on performance declines, because each sport and discipline covers a different spectrum of abilities such as speed, power, agility, and others.

\section{Acknowledgements}

We would like to thank the athletes for their contribution and everyone who makes master athletics possible for this wonderful sport and community!

\section{Conflicts of Interest}

The authors declare that they have no conflict of interest.

\section{References}

[1] Arampatzis A, Degens H, Baltzopoulos V, Rittweger J. Why do older sprinters reach the finish line later? Exerc Sport Sci Rev 2011; 39: $18-22$

[2] Bartlett RM, Best RJ. The biomechanics of javelin throwing: A review. J Sports Sci 1988; 6: 1-38
[3] Berthelot G, Len S, Hellard P, Tafflet M, Guillaume M, Vollmer JC, Gager $B$, Quinquis L, Marc A, Toussaint JF. Exponential growth combined with exponential decline explains lifetime performance evolution in individual and human species. Age 2012; 34: 1001-1009

[4] Best RJ, Bartlett RM, Morriss C]. A three-dimensional analysis of javelin throwing technique. J Sports Sci 1993; 11: 315-328

[5] Cheng S, Degens H, Evans M, Cheng SM, Selänne H, Rittweger ], Heinonen A, Suominen H, Strandberg T, Alen M, Korhonen MT. What makes a 97 -year-old man cycle 5,000 km a year? Gerontology 2016; 62: 508-512

[6] Degens H, Maden-Wilkinson TM, Ireland A, Korhonen MT, Suominen H, Heinonen A, Radak Z, McPhee JS, Rittweger J. Relationship between ventilatory function and age in master athletes and a sedentary reference population. Age (Dordr) 2013; 35: 1007-1015

[7] Degens H, Rittweger J, Parviainen T, Timonen KL, Suominen H, Heinonen A, Korhonen MT. Diffusion capacity of the lung in young and old endurance athletes. Int J Sports Med 2013; 34: 1051-1057

[8] Drey M, Sieber CC, Degens H, McPhee ], Korhonen MT, Müller K, Ganse B, Rittweger J. Relation between muscle mass, motor units and type of training in master athletes. Clin Physiol Funct Imaging 2016; 36: 70-76

[9] Harriss D], Macsween A, Atkinson G. Standards for ethics in sport and exercise science research: 2018 update. Int J Sports Med 2017; 38: $1126-1131$

[10] Korhonen MT, Cristea A, Alén M, Häkkinen K, Sipilä S, Mero A, Viitasalo JT, Larsson L, Suominen H. Aging, muscle fiber type, and contractile function in sprint-trained athletes. J Appl Physiol 2006; 101: 906-917

[11] Korhonen MT, Haverinen M, Degens H. Training and nutritional needs of the masters sprint athlete. In: Reaburn PRJ. ed. Nutrition and Performance in Masters Athletes. Boca Ration: CRC Press; 2015: 291-322

[12] Kunz H, Kaufmann DA. Cinematographical analysis of javelin throwing techniques of decathletes. Brit J Sports Med 1983; 17: 200-204

[13] Maden-Wilkinson TM, McPhee JS, Jones DA, Degens H. Age-related loss of muscle mass, strength, and power and their association with mobility in recreationally active older adults in the United Kingdom. J Aging Phys Act 2015; 23: 352-360

[14] Maryniak J, Ładyżyńska-Kozdraś E, Golińska E. Mathematical modeling and numerical simulations of javelin throw. Hum Mov 2009; 10: 16-20

[15] Menzel H]. Biomechanics of javelin throwing. IAAF 1986; 3: 85-98

[16] Piasecki M, Ireland A, Coulson J, Stashuk DW, Hamilton-Wright A, Swiecicka A, Rutter MK, McPhee JS, Jones DA. Motor unit number estimates and neuromuscular transmission in the tibialis anterior of master athletes: Evidence that athletic older people are not spared from age-related motor unit remodeling. Physiol Rep 2016; 4: pii: e12987

[17] Rittweger J, di Prampero PE, Maffulli N, Narici MV. Sprint and endurance power and ageing: An analysis of master athletic world records. Proc Biol Sci 2009; 276: 683-689

[18] Schmitt H, Hansmann H], Brocai DR, Loew M. Long-term changes of the throwing arm of former elite javelin throwers. Int J Sports Med 2001; 22: 275-279

[19] Stanković D, Joksimović A, Racović A, Piršl D. Influence of some motor abilities on the javelin throw success. Fizicka kultura (Skopje) 2010; 38: 95-97

[20] Viitasalo J, Mononen H, Norvapalo K. Release parameters at the foul line and the official result in javelin throwing. Sports Biomech 2003; 2: 15-34

[21] Wikipedia contributors. List of world records in masters athletics.In: Wikipedia, The Free Encyclopedia. Retrieved from https://en.wikipedia. org/wiki/List_of_world_records_in_masters_athletics 